\title{
PERSPECTIVE
}

\section{Hypertensive retinopathy revisited: some answers, more questions}

\author{
A Grosso, F Veglio, M Porta, F M Grignolo, T Y Wong
}

Br J Ophthalmol 2005;89:1646-1654. doi: 10.1136/bjo.2005.072546

Hypertension is associated with cardiovascular risk and systemic target organ damage. Retinopathy is considered one of the indicators of target organ damage. This review focuses on recent studies on hypertensive retinopathy and their implications for clinical care. Early recognition of hypertensive retinopathy signs remains an important step in the risk stratification of hypertensive patients.

See end of article for authors' affiliations

Correspondence to:

Correspondence to:
Andrea Grosso, MD, Department of Clinical Physiopathology, Ophthalmology Section, Turin University, Via Juvarra, 19, 10122 Turin, Italy; 78andrea1@tin.it

Accepted for publication 1 July 2005
Guidelines (BHS IV) ${ }^{15}$ consider retinopathy as target organ damage, although again only for grades III and IV.

There are a number of considerations that may militate against systematic retinal examination in patients with hypertension. These include vague definitions and heterogeneous classifications of hypertensive retinopathy, making severity staging a largely arbitrary process, as well as the lack of well defined prognostic value for either systemic outcomes or visual impairment.

\section{EPIDEMIOLOGY}

Several recent studies have shown that retinal microvascular changes can be reliably documented by retinal photographs. ${ }^{16-23}$ In general, reproducibility from photographs has been found to be excellent for well defined retinopathy signs (kappa values ranged from 0.80 to 0.99 for microaneurysms and retinal haemorrhages) and fair to moderate for other more subtle retinal arteriolar lesions $(0.40-0.79$ for arteriolar narrowing and arteriovenous nicking). ${ }^{24}$

Furthermore, these studies suggest that generalised arteriolar narrowing could be estimated from an assessment of retinal vessel diameters on photographs by use of imaging software. The development of specific software packages have made it possible to objectively measure the arteriole to venule ratio (AVR) in selected standardised portions of the retina. ${ }^{16}{ }^{17}$ This technique appears to have substantial reproducibility (intraclass correlation coefficient ranged from $0.80-0.99) .{ }^{17} 20-23$

On the basis of retinal photography, retinal microvascular signs are common in adults 40 years of age and older, even in those without history of diabetes and hypertension. Both prevalence and incidence of between 2-15\% have been reported for various retinal microvascular lesions. ${ }^{19-25}$

\section{WHAT RETINAL SIGNS ARE CLINICALLY USEFUL TO CLINICIANS FOR RISK ASSESSMENT?}

Data from population based studies indicate that certain signs of hypertensive retinopathy (table 3) are associated with increased cardiovascular risk,

Abbreviations: $A B P M$, ambulatory blood pressure monitoring; $\mathrm{AION}$, anterior ischaemic optic neuropathy; $A M D$, age related maculopathy; $A V R$, arteriole to venule ratio; $B P$, blood pressure; CHD, coronary heart disease; CVD, cardiovascular disease; IMT, intima-media thickness; LVH, left ventricular hypertrophy; MRI, magnetic resonance imaging; $\mathrm{RAO}$, retinal arterial occlusion; RVO, retinal vein occlusion; $\mathrm{WCH}$, white coat hypertension 
Table 1 Different prognostic classification of hypertensive retinopathy, according to the European Society of Hypertension-European Society of Cardiology (ESH-ESC) 2003 Guidelines, the JNC 7 Report, the British Hypertension Society (BHS) IV 2004 Guidelines, and the World Health Organization-International Society of Hypertension (WHO/ISH) 2003 statement on diagnosis and treatment of hypertension

\begin{tabular}{lll}
\hline ESH-ESC 2003 guidelines $^{12}$ & JNC 7 report 2003 & $\begin{array}{l}\text { WHO/ISH 2003 statement } \\
\text { BHS IV } 2004 \text { guidelines }^{13}\end{array}$ \\
\hline $\begin{array}{l}\text { Associated clinical conditions } \\
\begin{array}{l}\text { Advanced retinopathy: haemorrhages or } \\
\text { exudates, papilloedema }\end{array}\end{array}$ & $\begin{array}{l}\text { Target organ damage } \\
\text { Retinopathy }\end{array}$ & $\begin{array}{l}\text { Target organ damage } \\
\text { Hypertensive retinopathy grade III } \\
\text { or IV }\end{array}$ \\
\hline
\end{tabular}

independently of other risk factors. ${ }^{23}{ }^{26-28}$ Generalised and focal retinal arteriolar narrowing has been shown to predict the risk of hypertension in normotensive people. ${ }^{29-31}$ Generalised arteriolar narrowing (fig 1), focal arteriolar narrowing, arteriovenous nicking (fig 2), opacity (copper wire) of arteriolar wall, or a combination of these (mild grade of retinopathy) have been associated with a mild increase (odds ratio greater than 1 but less than 2) of incident clinical stroke, coronary heart disease, and death. The Atherosclerosis Risk in Communities Study showed that generalised arteriolar narrowing of the retinal arterioles was associated with subsequent coronary heart disease in women (relative risk, 2.2; 95 confidence interval 1.0 to 4.6 ) but not in men (relative risk, 1.1 ; 95 confidence interval 0.7 to 1.8$).^{32}$ Furthermore, in the ARIC Study generalised arteriolar narrowing of the retinal arterioles was found to be independently associated with increased risk for type 2 diabetes (odds ratio, 1.71; 95 confidence interval 1.13 to 2.57$).^{33}$

Haemorrhages (blot, dot, or flame shaped), microaneurysms, cottonwool spots, hard exudates (fig 3), or a combination of these signs (moderate grade of retinopathy) are more strongly associated (odds ratio of 2 or greater) with risk of incident clinical stroke, ${ }^{34}$ presence and severity of magnetic resonance imaging (MRI) defined cerebral white matter lesions and cerebral atrophy defined on MRI, ${ }^{35}$ reduced cognitive performance on standardised neuropsychological tests, $^{36}{ }^{37}$ and death from cardiovascular causes. ${ }^{28}$ The ARIC Study reported that people with microaneurysms, retinal haemorrhages, and soft exudates were two to three times more likely to develop an incident clinical stroke over 3 years than people without these retinal lesions, independently of blood pressure, diabetes, cigarette smoking, elevated lipid levels, and other risk factors. ${ }^{34}$ Furthermore, there was a multiplicative interaction between the presence of retinal microvascular changes and white matter lesions on the risk of stroke. The 5 year relative risk of stroke among participants who had both hypertensive retinopathy and cerebral lesions on MRI, compared with those who had neither of these findings, was 18.1 (confidence interval, 5.9 to 55.4);

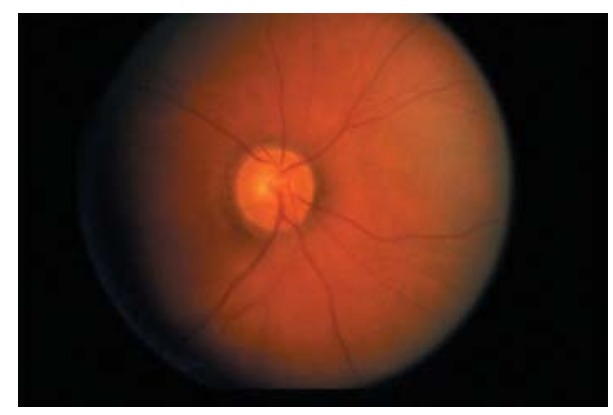

Figure 1 Mild hypertensive retinopathy. Photograph shows generalised retinal arteriolar narrowing.

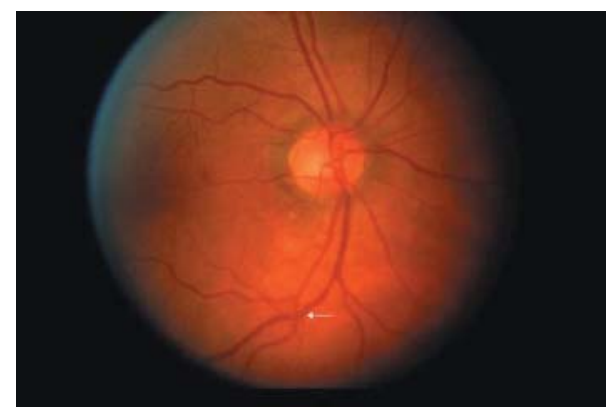

Figure 2 Mild hypertensive retinopathy. Photograph shows arteriovenous nicking (white arrow).

among participants who had white matter lesions only, the relative risk of stroke was 3.4 (confidence interval, 1.5 to 7.7)..$^{35}$

In a nested case-control study in patients with age related eye diseases in Wisconsin (the Beaver Dam Eye Study) the presence of retinal microaneurysms, retinal haemorrhages, and retinal arteriolar narrowing was associated with a high

Table 2 The Keith, Wagener, and Barker ${ }^{177}$ hypertensive retinopathy classification (grade I-IV), based on the level of severity of the retinal findings

\begin{tabular}{lll}
\hline Grade & Classification & Symptoms \\
\hline Grade I (mild hypertension) & $\begin{array}{l}\text { Mild generalised retinal arteriolar narrowing or } \\
\text { sclerosis }\end{array}$ & No symptoms \\
$\begin{array}{l}\text { Grade II (more marked hypertension } \\
\text { retinopathy) }\end{array}$ & $\begin{array}{l}\text { Definite focal narrowing and arteriovenous } \\
\text { crossings. Moderate to marked sclerosis of the } \\
\text { retinal arterioles. Exaggerated arterial light reflex }\end{array}$ & Asymptomatic \\
$\begin{array}{l}\text { Getinal haemorrhages, exudates and cotton wool III (mild angiospastic } \\
\text { retinopathy) }\end{array}$ & $\begin{array}{l}\text { spots. Sclerosis and spastic lesions of retinal } \\
\text { arterioles } \\
\text { Severe grade III and papilloedematic }\end{array}$ & Symptomaced survival \\
\hline
\end{tabular}


Table 3 Classification of hypertensive retinopathy by Wong and Mitchell ${ }^{26}$

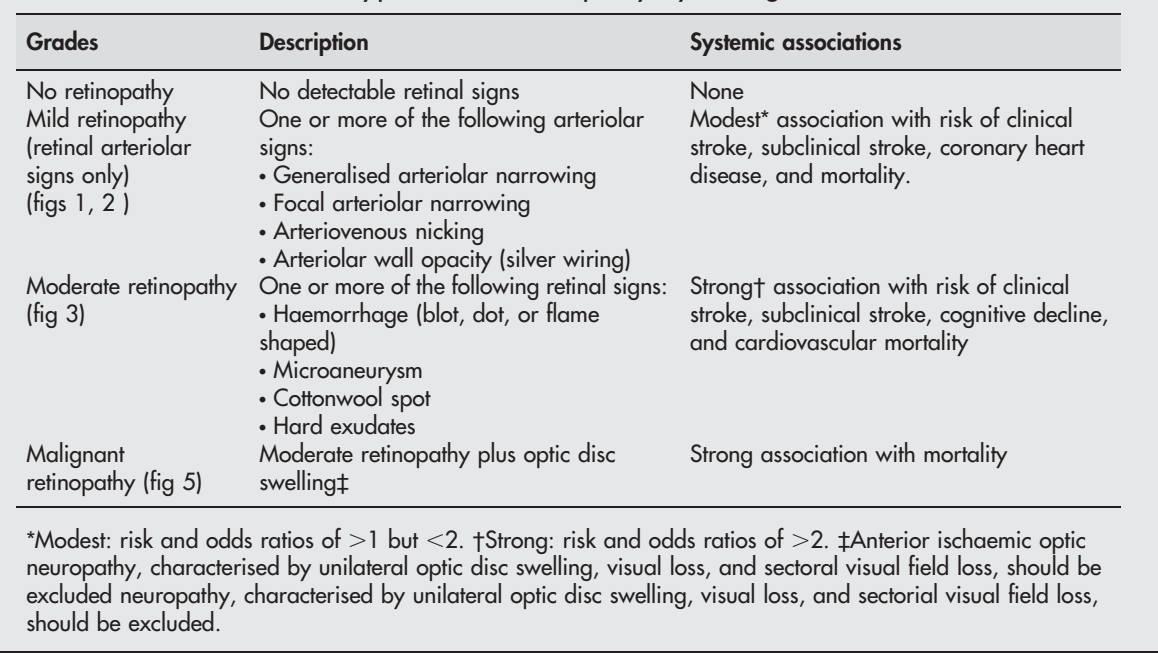

10 year risk of stroke mortality. ${ }^{28}$ In the Cardiovascular Health Study, people with similar signs of retinopathy were twice as likely to have a history of stroke as those who did not have these signs (odds ratio, 2.0; confidence interval, 1.1 to 3.6). ${ }^{22}$ Other population based studies reported that the risk of fatal and non-fatal stroke are two to three times as high in people do not have these signs, independently of cardiovascular risk factors. ${ }^{28} 38$

\section{WHY ARE SPECIFIC RETINAL SIGNS ASSOCIATED WITH DIFFERENT CARDIOVASCULAR COMPLICATIONS?}

Population based studies reported that mild and moderate grades of retinopathy correlate with different main outcome measures. ${ }^{18232628} 22-35$ This requires a plausible interpretation. It is possible that different manifestations of hypertensive retinopathy do not originate from the same pathogenic mechanism, and therefore predispose to different levels of cardiovascular risk. An alternative explanation is that, from a quantitative point of view, a higher degree of generalised vascular damage might bring together more severe retinal findings and more frequent main outcome measures.

Findings from the ARIC, Blue Mountains Eye, and Beaver Dam Eye studies 23262728 indicate that the pathogenesis of retinal arteriolar changes (focal narrowing, generalised arteriolar narrowing, and arteriovenous nicking) is distinct from that of more severe signs of hypertensive retinopathy (microaneurysms, haemorrhages, hard exudates, and cottonwool spots).

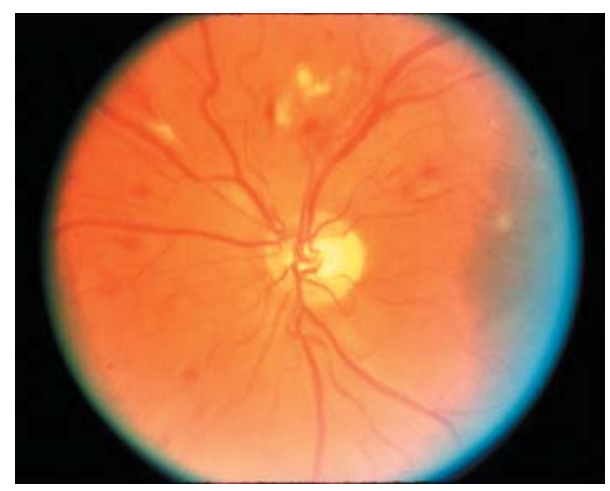

Figure 3 Moderate hypertensive retinopathy. Photograph shows cottonwool spots and retinal haemorrhages.
According to histopathological studies, ${ }^{39}$ generalised retinal arteriolar narrowing and arteriovenous nicking seem to be related to chronically high blood pressure. In the ARIC Study, independently of blood pressure, generalised arteriolar narrowing was also related to systemic markers of inflammation, whereas arteriovenous nicking was related to markers of inflammation and endothelial dysfunction and may reflect persistent structural damage from these processes. $^{232728} 40-42$ Endothelial function of the retinal vasculature is impaired in early essential hypertension. ${ }^{43}$ The role of nitric oxide in the maintenance of choroidal and retinal flow has been recently verified. ${ }^{44-50}$ L-NMMA reaction of retinal capillary flow is impaired in hypertensive patients ${ }^{43}$ and in patients with type 1 diabetes a reduced response of choroidal flow to L-NMMA has also been observed. ${ }^{51}$ Additionally, arteriolar narrowing and arteriovenous nicking were inconsistently associated with diabetes, glucose, and glycosylated haemoglobin. ${ }^{28}$

In contrast, hypertensive retinopathy was strong and consistently associated with diabetes, its duration, and its severity. In the ARIC Study hypertensive retinopathy was related to concurrent but not past blood pressure values. ${ }^{29}$ Microaneurysms, retinal haemorrhages, and soft exudates are most commonly seen when there is a breakdown of the blood-retinal barrier.

Thus, a possible explanation for these data is that mild hypertensive retinopathy reflects cardiovascular disease (CVD) risk in relation to chronic effects of elevated blood pressure, whereas moderate grade of hypertensive retinopathy reflects CVD risk in relation to diabetes, glycaemia, and to recently diagnosed, more severe hypertension. ${ }^{28}{ }^{52}$ Furthermore, the prognostic significance of specific retinal vascular abnormalities may vary with age. The fact that arteriovenous nicking was almost twice as frequent in younger people $(6.5 \%)$ than older people $(3.3 \%)$ who died of CVD causes is consistent with such a hypothesis. ${ }^{28}$

\section{HYPERTENSION AND DIABETES}

Diabetes and hypertension are both vascular risk factors and may share similar pathophysiological mechanisms. Both conditions are also linked by the metabolic syndrome. ${ }^{53} 54$ The prevalence of diabetes among patients with hypertension is high, ${ }^{55}$ and type 2 diabetes may remain unrecognised for years before being diagnosed. ${ }^{56}$ When diabetes is associated with hypertension, cardiovascular risk rises exponentially and retinopathy becomes more severe and rapidly progressive. In turn, more tight control of blood pressure in 
hypertensive diabetic people was shown to prevent cardiovascular events as well as deterioration of both retinopathy and visual acuity..$^{57-59}$ Among the various pathophysiological mechanisms, endothelial dysfunction has been implicated in the pathogenesis of the metabolic syndrome and points to a link between diabetes and hypertension. ${ }^{60}{ }^{61}$ It was observed ${ }^{51}$ that systemic and ocular haemodynamic reactivity to NOsynthase inhibition is reduced in patients with long standing insulin dependent diabetes mellitus, compared with healthy control subjects The blunted response of retinal capillary flow to L-NMMA observed ${ }^{43}$ in young hypertensive patients with essential hypertension indicates a reduced contribution of nitric oxide to the maintenance of retinal perfusion. ${ }^{43}$ Therapy with ATl receptor blocker candesartan celexitil restored both the contribution of nitric oxide to the maintenance of retinal perfusion and nitric oxide dependent vasodilation in the retinal vasculature of patients with arterial hypertension. ${ }^{43}$ Other mechanisms linking diabetes and hypertension are inflammatory processes and overt atherosclerosis. ${ }^{62}{ }^{63}$

\section{DO RETINAL SIGNS CORRELATE WITH HYPERTENSION SEVERITY?}

A correlation between retinal lesions, as detected by direct ophthalmoscopy, and left ventricular hypertrophy, as defined by echocardiography, was suggested ${ }^{64}$ but the study was limited by the imprecision of clinical ophthalmoscopy in quantifying retinal arteriolar narrowing and by the rather small sample size. Some studies have linked renal dysfunction with retinal vascular changes, ${ }^{65-68}$ but the relation of early retinal vessel vascular changes and risk of cardiovascular complications is not well understood.

Recent findings from a clinical study ${ }^{69}$ showed no significant relation between retinal microvascular changes (diffuse arteriolar narrowing, arteriovenous crossings), detected by qualitative examination of the fundus, and prognostically validated markers of target organ damage, such as 24 hour ambulatory blood pressure monitoring, 24 hour urine collection for microalbuminuria, echocardiography, carotid ultrasonography in early stages of untreated essential hypertension. Early retinal alterations were extremely frequent in this cohort of relatively young untreated subjects with recently diagnosed grade 1 or 2 hypertension. Furthermore, the prevalence of retinal microvascular abnormalities was much higher than that of left ventricular hypertrophy, carotid wall alterations, and microalbuminuria. ${ }^{69-71}$ Patients with arteriovenous crossings did not have more cardiac, carotid, and renal alterations compared with those without this retinal pattern. The distribution of retinal microvascular changes was similar in lower, intermediate, or higher tertiles of left ventricular mass.

\section{THE ROLE OF SYSTEMIC HYPERTENSION AS A RISK FACTOR FOR OTHER EYE DISEASES SUCH AS GLAUCOMA OR AGE RELATED MACULAR DEGENERATION}

In addition to hypertensive retinopathy, elevated blood pressure is a risk factor for many ocular conditions. These include anterior ischaemic optic neuropathy, retinal vein occlusion, retinal arteriolar emboli and, possibly, age related maculopathy (AMD) and glaucoma. ${ }^{72}$ With regard to AMD, the Framingham Study ${ }^{73}$ reported an association of AMD with systemic hypertension, a relation that increased with the duration of the hypertension. ${ }^{73}$ However, other studies have not found consistent relations. No such correlation was found for the development of the neovascularisation in the studies by Bressler, ${ }^{74}$ the Eye Disease Case Control Study Group, ${ }^{75}$ and the Beaver Dam Eye Study. ${ }^{76}$ More recently, the Macular Photocoagulation Study ${ }^{77}$ found a relative risk of 1.7 for the development of choroidal neovascularisation in patients with definite systemic hypertension. Over 5 years, the incidence of choroidal neovascularisation was $49 \%$ among patients with definite hypertension versus 33\% in patients without definite hypertension. The authors stressed the importance of high blood pressure on the prognosis of the fellow eye. With regards to glaucoma, a population based study $^{78}$ showed a modest positive association of primary open angle glaucoma with systolic and diastolic blood pressure. In another study, ${ }^{79}$ however, no correlation was showed in the prevalence of arterial hypertension in primary and secondary open angle glaucoma.

\section{Are retinal examinations more useful in specific subgroups of populations?}

There is strong evidence that identifying and targeting subsets of hypertensive patients at highest risk improves the cost effectiveness of antihypertensive treatment. ${ }^{80}$ Subjects with white coat hypertension (WCH) or masked hypertension-that is, the phenomenon of consistently elevated clinic blood pressure levels but normal 24 hours ambulatory blood pressure monitoring, ${ }^{81}$ may represent an intermediate group between healthy people and sustained hypertensives as far as target organ damage and cardiovascular risk is concerned. Prevalence of this condition is quite variable, depending of the selection groups, suggesting a range between $12 \%-30 \%$, being more common in the elderly ${ }^{82}$ and among females. ${ }^{82}$ Previous studies have suggested that WCH is associated with end organ damage. ${ }^{82} 83$

The presence of hypertensive retinopathy in WCH may suggest an indication to antihypertensive therapy.

Evidence is increasing that even mild blood pressure (BP) elevation can have an adverse effect on vascular structure and function in asymptomatic young people. High BP in childhood had been considered a risk factor for hypertension in early adulthood. The retinal examination is recommended to identify retinal vascular changes in young patients with co-morbid risk factors and BP 90th-94th percentile and in all patients with $\mathrm{BP} \geqslant 95$ th percentile. ${ }^{84-89}$ A previous study reported a prevalence of $41 \%$ for the arteriolar narrowing and of $8 \%$ for arteriovenous nicking, as defined by retinal photographs, in a cohort of 97 children and adolescents with essential hypertension. ${ }^{90}$ Further longitudinal studies will be necessary to determine how these retinal vascular signs progress over time in juveniles with essential hypertension and whether the abnormalities are of prognostic importance. ${ }^{91}$ Finally, it is unclear whether retinal examination would confer a greater benefit in women and black people. ${ }^{26}$

\section{WHAT SHOULD CLINICIANS DO WITH THE CURRENT EVIDENCE?}

On the basis of the available data we propose a flow chart about the supplemental risk assessment by the ophthalmoscopic consultation in hypertensive subjects (fig 4). The strongest evidence of the usefulness of hypertensive retinopathy for risk stratification is based on its association with stroke (tables 3-5). ${ }^{26}{ }^{34}{ }^{35}$ In the presence of equivocal signs (borderline or inconsistent hypertension or WCH with no other evidence of target organ damage) or visual symptoms, an examination by the ophthalmologist may be useful. The presence of retinopathy may be an indication for initiating antihypertensive treatment. ${ }^{12}{ }^{13}{ }^{26}$ For hypertensive patients grade $2^{12}$ without overt target organ damage ophthalmological referral may also be useful. The presence of retinopathy may be an indication for more aggressive intervention on associated cardiovascular risk factors and co-morbidities and has an important practical impact for treatment decisions (for example, antihypertensive and anti-platelet aggregation) and for close follow up. Furthermore, for some patients, ophthalmic consultation may be useful to rule out diabetic 


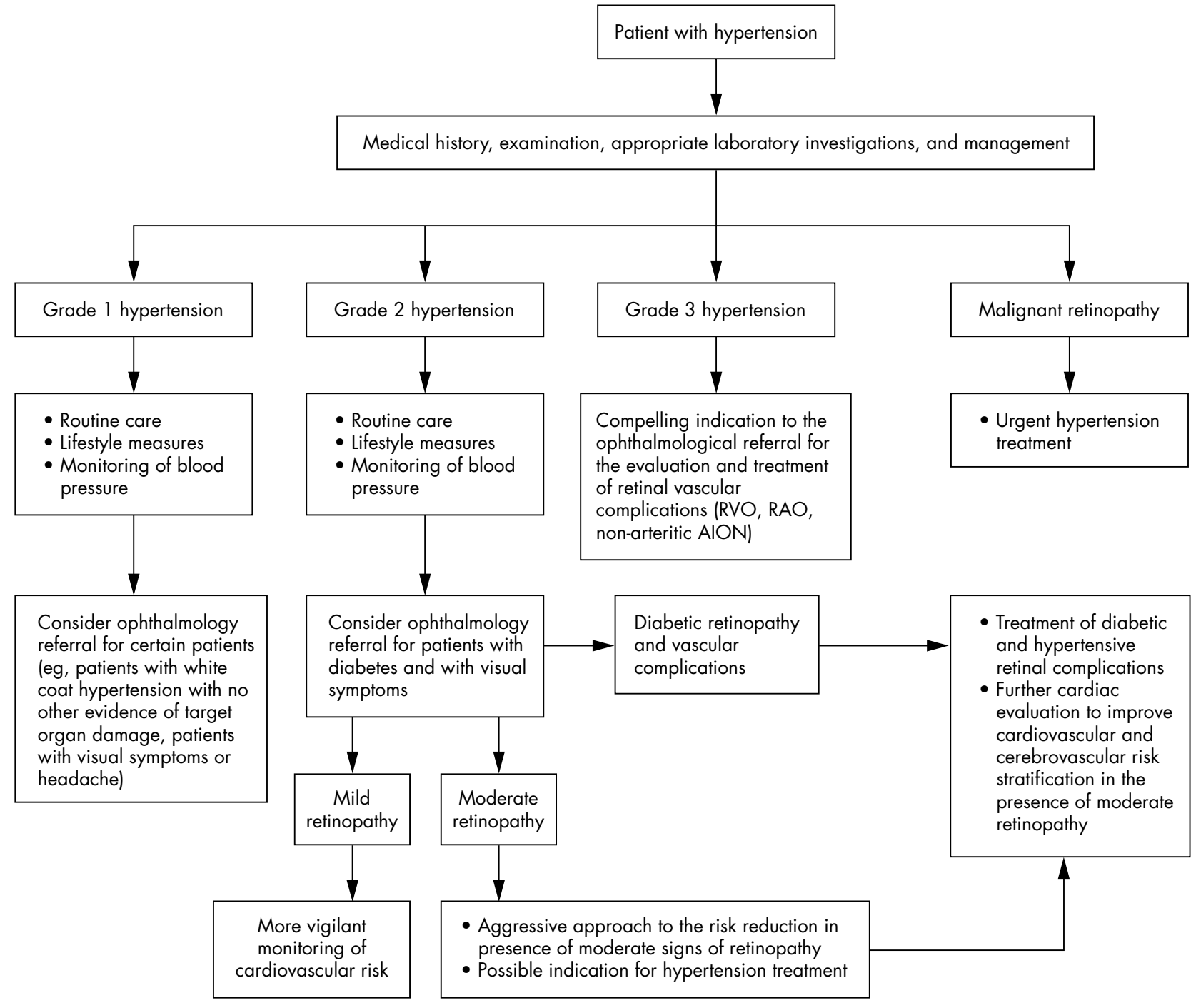

Figure 4 Flow chart: supplemental risk assessment by retinal examination.

retinopathy, retinal vein occlusion, anterior ischaemic optic neuropathy, or retinal arterial occlusion. ${ }^{44}{ }^{26}$ For all grade 3 hypertensive patients ${ }^{12}$ there are compelling indications for an ophthalmological referral (fig 5) for evaluation and treatment of retinal vascular complications. ${ }^{92}$ In WCH the ophthalmological referral may be indicated when there is no other evidence of target organ damage. In the presence of both mild and moderate (table 3 ) retinal signs, pharmacological treatment may be warranted. In the presence of moderate retinal signs (table 3) ophthalmologists may refer people for further cardiac evaluation to improve the cerebrovascular risk stratification. ${ }^{93}$

\section{LIMITATIONS OF AVAILABLE DATA}

Epidemiological studies provide additional insight that arteriolar constriction and narrowing may have a critical role in the development of hypertension. However, caution must be applied to the interpretation of these data.

Firstly, raised intraocular pressure may affect retinal arteriolar calibre. The ARIC Study did not include an assessment of IOP. ${ }^{94-96}$

Secondly, photographs were not synchronised with the cardiac cycle and vessel diameter may vary because of pulsatility. A variation of $2 \%$ to $17 \%$ has been described. ${ }^{97} 98$ However, because photography was independent of any

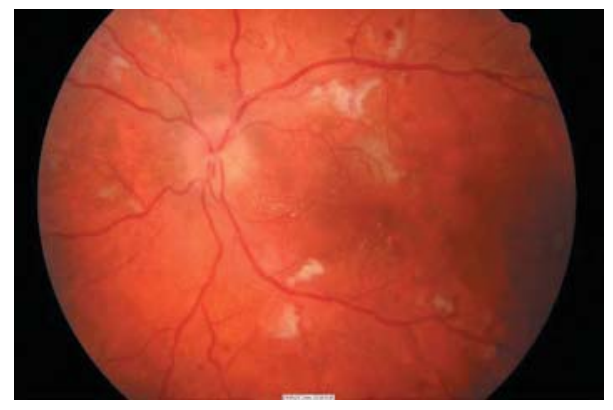

Figure 5 Malignant hypertensive retinopathy. Photograph shows multiple cotton wool spots, retinal haemorrhages, optic disc swelling, and macular star.

subject characteristics, this variation, at most, would have caused random misclassification. The optimal conditions for taking measurements, with reference to posture, ${ }^{99}$ blood pressure, ${ }^{100}$ and autonomic nervous system, ${ }^{101}$ also need to be standardised. Furthermore, pregnancy induces modifications on the vascular dynamics. ${ }^{102}$

Thirdly, the overall prevalence of retinopathy signs in some recently reported studies may be too high. ${ }^{69}$ It is unclear 
Table 4 Mild hypertensive retinopathy (retinal arteriolar signs only)

\begin{tabular}{|c|c|c|c|c|}
\hline Sign & Diagnosis & Histopathology correlations & Clinical correlations & Future research \\
\hline $\begin{array}{l}\text { Generalised } \\
\text { arteriolar } \\
\text { narrowing }\end{array}$ & $\begin{array}{l}\text { - Qualitative examination of } \\
\text { retinal photographs } \\
\text { - Computer assisted fundus } \\
\text { image analysis and AVR } \\
\text { calculation in selected } \\
\text { standardised portions of } \\
\text { the retina } \\
1617\end{array}$ & $\begin{array}{l}\text { - Vasoconstrictive phase: } \\
\text { vasospasm and an increase } \\
\text { in retinal arteriolar tone } \\
\text { - Sclerotic phase: intimal } \\
\text { thickening, hyperplasia of } \\
\text { the tunica media, and } \\
\text { hyaline degeneration in the } \\
\text { subsequent sclerotic stage }\end{array}$ & $\begin{array}{l}\text { - Risk of hypertension (odds ratio, } \\
1.62 ; \mathrm{Cl} 95 \% 1.21 \text { to } 2.18)^{29-31} \\
\text { - Risk of stroke (relative risk, } 1.24 \text {, } \\
\mathrm{Cl} 95 \% 0.66 \text { to } 2.31)^{34} 35 \\
\text { - Risk of CHD in women (relative } \\
\text { risk, } 1.37 ; \mathrm{Cl} 95 \% 1.08 \text { to } 1.72)^{32} \\
\text { - Risk of diabetes mellitus (odds } \\
\text { ratio, } 1.71, \mathrm{Cl} 95 \% 1.13 \text { to } 2.57)^{33} \\
\text { - Relation to stiffness of the } \\
\text { carotid arteries }^{116} \\
\text { Risk of cognitive } \\
\text { impairment:modest association }\end{array}$ & $\begin{array}{l}\text { Clinical validation of the AVR } \\
\text { Clinical significance } \\
\text { (a) CVD evaluation in presence } \\
\text { of retinal mcrovascular lesions } \\
\text { (b) Potential value of } \\
\text { specifically targeting the } \\
\text { microcirculation in the } \\
\text { treatment of hypertension } \\
\text { Prevention } \\
\text { (c) Role of retinal photography } \\
\text { for CVD risk stratification }\end{array}$ \\
\hline $\begin{array}{l}\text { Focal arteriolar } \\
\text { narrowing }\end{array}$ & $\begin{array}{l}\text { - Constricted area of two } \\
\text { thirds or less the width of } \\
\text { proximal and distal vessel } \\
\text { segments }\end{array}$ & $\begin{array}{l}\text { - Areas of localised } \\
\text { vasoconstriction evaluated } \\
\text { on the disc and within } 1 / 2 \\
\text { DD of its margin zone }{ }^{17}\end{array}$ & $\begin{array}{l}\text { - Risk of any stroke (relative risk } \\
\text { crude, } 1.57, \mathrm{Cl} 95 \%, 1.0 \text { to } \\
2.45)^{34} 35 \\
\text { - Risk of cognitive } \\
\text { impairment:modest association }{ }^{36}\end{array}$ & $\begin{array}{l}\text { Prevention } \\
\text { Usefulness of focal arteriolar } \\
\text { narrowing evaluation in the } \\
\text { cerebrovascular risk } \\
\text { stratification }\end{array}$ \\
\hline $\begin{array}{l}\text { Arteriovenous } \\
\text { nicking }\end{array}$ & $\begin{array}{l}\text { - Present if seen in at least one of } \\
\text { the temporal quadrants; definite } \\
\text { if the venous blood column was } \\
\text { tapered on both sides of its } \\
\text { crossing under an arteriole; } \\
\text { EDTRS standard photograph } 9^{17}\end{array}$ & $\begin{array}{l}\text { Sclerotic phase: intimal } \\
\text { thickening, hyperplasia of } \\
\text { the tunica media, and } \\
\text { hyaline degeneration in the } \\
\text { subsequent sclerotic stage }\end{array}$ & $\begin{array}{l}\text { - Risk of any stroke (relative risk, } \\
2.21, \mathrm{Cl} 95 \%, 1.44 \text { to } 3.38)^{34} 35 \\
\text { - Risk of cognitive } \\
\text { impairment:modest association }^{36}\end{array}$ & $\begin{array}{l}\text { - Prevention } \\
\text { Usefulness of arteriovenous } \\
\text { nicking evaluation in the } \\
\text { cerebrovascular risk } \\
\text { stratification in hypertensives }\end{array}$ \\
\hline
\end{tabular}

how these changes were defined and how signs were classified. Moreover, the terminology used is neither consistent nor comparable with data from other population based studies. The recommendations issued by ESH-ESC $2003^{12}$ do not take in account recent data from epidemiological studies, but are derived only from the conclusion of one clinical study. ${ }^{70}$ Fourthly, there are no reliable clinical data to relate signs of retinopathy with other prognostically validated markers of target organ damage, such as intima-media thickness (IMT), left ventricular hypertrophy (LVH), and ABPM. Reclassification of cardiovascular risk recently proposed ${ }^{69}$ taking into account the evaluation of the arteriovenous nicking, is biased by the cross sectional design of the study. Finally, from a methodological viewpoint, retinal photographs in those large population based studies were evaluated in standardised settings, which are typical of clinical research but may not be transferred easily to everyday practice.

\section{WHAT ARE FUTURE RESEARCH QUESTIONS?}

Researchers should develop a common and standardised photographic classification of the retinal signs similar to diabetic retinopathy.

Secondly, the ARIC study offers insights that support the hypothesis that microvascular disease may have a more prominent role in the development of myocardial ischaemia and coronary heart disease (CHD) in women. However, this and other population base studies are prevented from making a more definite conclusion because they assessed retinal microvasculature, not the coronary or cerebral microcirculation. In addition, data from population base studies do not necessary imply a cause (generalised arteriolar narrowing)

Table 5 Moderate hypertensive retinopathy

\begin{tabular}{|c|c|c|c|c|}
\hline Sign & Diagnosis & Histopathology correlations & Clinical correlations & Future research \\
\hline Microaneurysm & Present $v$ absent & $\begin{array}{l}\text { Exudative phase: disruption of } \\
\text { blood-barrier, degeneration of } \\
\text { vascular smooth muscle and } \\
\text { endothelial cell necrosis } \\
\text { leading to blood and lipid } \\
\text { exudation and ischaemia }\end{array}$ & $\begin{array}{l}\text { - Risk of any stroke (relative risk, } 6.11 \text {; } \\
\mathrm{Cl} 95 \% 3.72 \text { to } 10.05)^{34} \\
\text { - Risk of cognitive impairment :strong } \\
\text { association }^{36}\end{array}$ & $\begin{array}{l}\text { Prevention } \\
\text { - Is retinal photography useful in the } \\
\text { measurement of stroke risk? }\end{array}$ \\
\hline $\begin{array}{l}\text { Retinal } \\
\text { haemorrhage (blot, } \\
\text { dot, or } \\
\text { flame,shaped) }\end{array}$ & $\begin{array}{l}\text { - Blot } \\
\text { - Flame shaped } \\
\text { - Both }\end{array}$ & - Exudative phase & $\begin{array}{l}\text { - Risk of any stroke (relative risk, } 6.44 \text {; } \\
\mathrm{Cl} 95 \% 3.61 \text { to } 11.49)^{34} \\
\text { - Risk of any stroke (relative risk, } 6.38 \text {; } \\
\mathrm{Cl} 95 \% 2.97 \text { to } 13.73)^{34} \\
\text { - Risk of cognitive impairment:strong } \\
\text { association }\end{array}$ & $\begin{array}{l}\text { Prevention } \\
\text { (a) Is retinal photography useful in the } \\
\text { measurement of stroke risk? } \\
\text { (b) Cognitive impairment may be } \\
\text { amenable to treatment and prevented } \\
\text { strategies targeted at vascular diseases }\end{array}$ \\
\hline Soft exudates & Present $v$ absent & $\begin{array}{l}\text { Ischaemia of the nerve fibre } \\
\text { layer }\end{array}$ & $\begin{array}{l}\text { - Risk of any stroke (relative risk } 7.80 \text {, } \\
\mathrm{Cl} 95 \% 4.07 \text { to } 14.96)^{34} \\
\text { - Risk of cognitive impairment:strong } \\
\text { association }\end{array}$ & $\begin{array}{l}\text { Prevention } \\
\text { - It is important to replicate some of these } \\
\text { findings in other populations to assess the } \\
\text { associations of retinal microvascular } \\
\text { disease to different stroke subtypes and to } \\
\text { other clinical and subclinical cerebral } \\
\text { disorders with a supposed microvascular } \\
\text { aetiology }\end{array}$ \\
\hline
\end{tabular}


and effect (incident CHD and stroke) relation. Thus, it is unclear why the association of generalised arteriolar narrowing was not associated with incident CHD in men. Further investigation is required to support the hypothesis that microvascular disease has a more prominent role in development of myocardial ischaemia and CHD in women. ${ }^{103}$ Other unmeasured factors (for example, use of vasodilator medications, diurnal and nocturnal fluctuations of blood pressure) associated with generalised arteriolar narrowing of retinal arterioles might have caused incident CHD or the stroke. ${ }^{103}$

Thirdly, the ARIC Investigators have shown that generalised retinal arteriolar narrowing may precede the onset of diabetes mellitus in middle aged people and may even have a role in its initial development. However, the authors have only shown a short term association between generalised arteriolar narrowing of the retinal arterioles and incident diabetes. Further studies are required to determine whether longer term associations do exist.

Fourthly, there has not been a consistent demonstration that these retinal signs have independent predictive value and that the addition of retinal photography may help to optimise global risk evaluation in primary hypertension and modify the therapeutic decisions. ${ }^{26}$

Finally, population based studies suggest that narrowed arterioles are associated with the development of hypertension and therefore that small vessel disease may be a target for antihypertensive treatment. ${ }^{104-107}$ Thus, there is a need to evaluate whether specific therapy focused on the retinal microcirculation can reverse ${ }^{108}$ change in retinopathy or reduce retinal microvascular damage, ${ }^{43} 109$ and, if so, whether this approach will also result in a reduced cardiovascular risk.

\section{NEW WAYS TO DETECT HYPERTENSIVE MICROVASCULAR DAMAGE: GENERALISED ARTERIOLAR NARROWING AS AN EXAMPLE OF FUTURE TECHNOLOGY}

A quantitative way of assessing one of the microvascular changes-generalised arteriolar narrowing in the retina-has been developed and used in population based studies. ${ }^{16}{ }^{19-22}$ The photographs were digitised and the diameters of individual arterioles and venules coursing through a zone located $1 / 2-1$ disc diameter from the optic disc margin were measured with a dedicated software and summarised as an arteriole-venule ratio (AVR). Use of the ratio was introduced to counter several potential problems. Firstly, it introduces some adjustment for the wide range of vessel diameter in the normal population. Secondly, by virtue of being a ratio it offers some protection against several potential problems: (a) variable magnification caused by differences in refractive error among individuals, (b) apparent broadening of vessel calibre as a result of poor photographic focus or ocular media clarity, and (c) differences among graders regarding the precise determination of the vessel edge.

It remains unclear what exactly the separate arteriolar and venular diameters contributed to the AVR and what kind of vascular disease this ratio precisely reflects. In the ARIC, Beaver, and Blue Mountains Eye Study the authors attributed a lower AVR to generalised arteriolar narrowing. Data from the Rotterdam Study indicate that the AVR does not reflect only generalised arteriolar narrowing but also a separate contribution from venular diameters. The authors hypothesise other pathogenic mechanisms related to the disruption of the endothelial surface layer and to inflammatory processes. ${ }^{110-112}$

Findings from the Wisconsin Epidemiologic Study of Diabetic Retinopathy ${ }^{113} 114$ showed that in eyes with nonproliferative diabetic retinopathy, measurement of venous dilation may add prognostic information independently of the severity scale. Wider retinal venular diameters have been suggested to reflect hyperperfusion resulting from both hyperglycaemia and retinal hypoxia. ${ }^{115}$ Thus, in future research, more attention should be paid to the role of venules in vascular disease.

\section{CONCLUSION}

In conclusion, hypertensive retinopathy remains a recognised manifestation of target organ damage in hypertensive patients. ${ }^{118}$ Digital retinal photography aimed at the automated measurement of retinal arteriolar diameter is useful in research on the microvascular contributions to clinical cardiovascular disease. In the future, a retinal examination might acquire a specific indication to predict (that is, consider CVD evaluation in presence of retinal microvascular lesions) and prevent (that is, role of retinal photography for CVD risk stratification) metabolic and/or cardiovascular events in the general population, even in the absence of overt hypertension or diabetes.

\section{Authors' affiliations \\ A Grosso, F M Grignolo, Department of Clinical Physiopathology, Ophthalmology Section Turin University, Italy \\ F Veglio, Department of Medicine and Experimental Oncology, Turin University, Italy \\ M Porta, Department of Internal Medicine, Turin University, Italy \\ T Y Wong, Centre for Eye Research Australia, University of Melbourne, Australia, and Singapore Eye Research Institute, National University of Singapore, Singapore}

\section{REFERENCES}

1 Chobanian AV. Control of hypertension-an important national priority. [Editorial] N Engl J Med, 2001;345:534-5.

2 Wolf-Maier K, Cooper RS, Banegas JR, et al. Hypertension prevalence and blood pressure levels in 6 European countries, Canada, and the United States. JAMA 2003;289:2363-9.

3 Gorelick PB. New horizons for stroke prevention PROGRESS and HOPE. Lancet Neurology 2002;1:149-56.

4 Wolf-Maier K, Cooper RS, Kramer, et al. Hypertension treatment and control in five European countries, Canada, and the United States. Hypertension 2004;43:10-17, Epub 2003 Nov 24.

5 Giampaoli S, Palmieri L, Chiodini P, et al. The global cardiovascular risk chart. Ital Heart J Suppl 2004:5:177-85.

6 Tso M, Jampol Lee M. Pathophysiology of hypertensive retinopathy. Ophthalmology 1982;89:1132-45.

7 Dollery CT, Ramalho PS, Patterson JW. Retinal vascular alterations in hypertension. In: Gross F, ed. Antihypertensive therapy; principles and practice, an international symposium. New York: Springer, 1966:152.

8 Goto I, Kimoto K, Katsuki S, et al. Pathological studies on the intracerebral and retinal arteries in cerebrovascular and non cerebrovascular diseases. Stroke 1975:6:263-9.

9 Wells RE, Herman M, Gorlin R. Microvascular changes in coronary heart disease. Circulation 1966;237:33-4.

10 Wise GN, Dollery CT, Henkind P. The retinal circulation. New York: Harper and Row, 1971:325.

11 Chatteriee S, Chattopadhya S, Hope-Ross M, et al. Hypertension and the eye: changing perspectives. J Human Hypertens 2002;16:667-75.

12 Guidelines Committee. 2003 European Society of Hypertension/ European Society of Cardiology guidelines for the management of arterial hypertension. J Hypertension 2003;21:1011-53.

13 Chobonian AV, Bakris GL, Black HR, et al. Seventh Report of the Joint National Committee on prevention, detection, evaluation, and treatment of high blood pressure. Hypertension 2003;42:1206-52.

14 World Health Organization/International Society of Hypertension Writing Group. 2003 World Health Organization (WHO)/International Society of Hypertension (ISH) Statement on Management of Hypertension. J Hypertens 2003;21:1983-92.

15 Williams B, Poulter NR, Brown MJ, BHS guidelines working party, for the British Hypertension Society, et al. British Hypertension Society guidelines for hypertension management 2004 (BHS-IV): summary. BMJ 2004:328:634-40.

16 Sharrett AR, Hubbard LD, Cooper, et al. Retinal arteriolar diameters and elevated blood pressure. The Atherosclerosis Risk in Communities Study. Am J Epidemiol 1999; 150:263-70.

17 Hubbard L, Brothers RJ, King WL, et al. Methods for evaluation of retinal microvascular abnormalities associated with hypertension/sclerosis in the Atherosclerosis Risk in Communities Study. Ophthalmology 1999; 106:2269-80. 
18 Wong TY, Klein R, Klein BEK, et al. Retinal microvascular abnormalities and their relations with hypertension, cardiovascular diseases and mortality. Surv Ophthalmol 2001;46:59-80.

19 Klein R, Klein BEK, Moss SE. The relation of systemic hypertension to changes in the retinal vasculature: the Beaver Dam Eye Study. Trans Am Ophthalmol Soc 1997; 95:329-48.

20 Wang JJ, Mitchell $\mathrm{P}$, Leung $\mathrm{H}$, et al. Hypertensive retinal wall signs in a general older population: the Blue Mountains Eye Study. Hypertension 2003;42:534-41.

21 Wong TY, Klein R, Klein BE, et al. Retinal vessel diameters and their associations with age and blood pressure. Invest Ophthalmol Vis $\mathrm{Sci}$ 2003;44:4644-50

22 Wong TY, Hubbard LD, Klein R, et al. Retinal microvascular abnormalities and blood pressure in older people: the Cardiovascular Health Study. Br J Ophthalmol 2002;86:1007-13.

23 Klein R, Sharrett AR, Klein BE, et al. Are retinal arteriolar abnormalities related to atherosclerosis? The Atherosclerosis Risk in Communities Study. Arterioscler Thromb Vasc Biol 2000;20:1644-50.

24 Couper DJ, Klein R, Hubbard L, et al. Reliability of retinal photography in the assessment of retinal microvascular characteristics. The Atherosclerosis Risk in Communities Study. Am J Ophthalmol 2002;133:78-88.

25 Stolk RP, Vingerling JR, de Jong PT, et al. Retinopathy, glucose, and insulin in an elderly population: the Rotterdam Study. Diabetes 1995;44:11-15.

26 Wong TY, Mitchell P Hypertensive retinopathy. N Engl J Med 2004;351:2310-17.

27 Leung $\mathrm{H}$, Wang JJ, Rochtchina $\mathrm{E}$, et al. Dyslipidaemia and microvascular disease in the retina. Eye 2004 Sep 3; Epub ahead of print.

28 Wong TY, Klein R, Nieto FJ, et al. Retinal microvascular abnormalities and ten-year cardiovascular mortality. A population-based case-control study. Ophthalmology 2003;1 10:933-40.

29 Wong TY, Klein R, Sharrett AR, et al. Atherosclerosis Risk in Communities Study. Retinal arteriolar diameter and risk for hypertension. Ann Intern Med 2004; 140:248-55

30 Wong TY, Shankar A, Klein R, et al. Prospective cohort study of retinal vessel diameters and risk of hypertension. BMJ 2004;329:79.

31 Smith W, Wang JJ, Wong TY, et al. Retinal arteriolar narrowing is associated with 5-year incident sever hypertension: the Blue Mountains Eye Study Hypertension. 2004;44:442-7, Epub 2004 Aug 09

32 Wong TY, Klein R, Sharrett AR, et al. Retinal arteriolar narrowing and risk of coronary heart disease in men and women: the Atherosclerosis Risk in Communities Study. JAMA 2002;287:1153-9.

33 Wong TY, Klein R, Sharrett AR, et al. Retinal arteriolar narrowing and risk of diabetes in middle-aged persons. JAMA 2002;287:2528-53

34 Wong TY, Klein R, Couper DJ, et al. Retinal microvascular abnormalities and incident stroke. The Atherosclerosis Risk in Communities Study. Lancet 2001;358:1134-40.

35 Wong TY, Klein R, Sharret R, et al. Cerebral white matter lesions, retinopathy, and incident clinical stroke. JAMA 2002;288:67-74.

36 Wong TY, Klein R, Sharret R, et al. Retinal microvascular abnormalities and cognitive impairment in middle aged persons. The Atherosclerosis Risk in Communities Study. Stroke 2002;33:1487-92.

37 Tekin O, Cukur S, Uraldi C, et al. Relationship between retinopathy and cognitive impairment among hypertensive subjects. A case-control study in the Ankara-Pursaklar region. Eur Neurol 2004;52:156-61.

38 Nakayama T, Date C, Yokoyama T, et al. 15.5 Year follow up study of stroke in a Japanese provincial city. The Shibata Study. Stroke 1997;28:45-52.

39 Garner A, Ashton N, Tripathi T, et al. Pathogenesis of hypertensive retinopathy. An experimental study in the monkey. Br J Ophthalmol 1982;89:1 132-45.

40 Conlan MG, Folsom AR, Finch A. Associations of factor VIII and von Willebrand factor with age, race, sex and risk factors for atherosclerosis. Thromb Haemost 1993;70:380-5.

41 Gabay C, Kushner I. Acute-phase proteins and other systemic responses to inflammation. N Engl J Med 1999;340:448-54.

42 Mannucci PM. von Willebrand factor: a marker of endothelial damage? Arteriosd Thromb Vasc Biol 1998;18:1359-62.

43 Delles C, Michelson G, Harazny J, et al. Impaired endothelial function of the retinal vasculature in hypertensive patients. Stroke 2004;35:1289-93, Epub 2004 Apr 08.

44 Koss MC. Functional role of nitric oxide in regulation of ocular blood flow. Eur J Pharmacol 1999;374:161-74.

45 Schmetterer L, Polak K. Role of nitric oxide in the control of ocular blood flow. Prog Retin Eye Res 2001;20:823-47.

46 White RP, Vallance P, Markus HS. Effect of inhibition of nitric oxide synthase on dynamic cerebral autoregulation in humans. Clin Sci (Lond) 2000;99:555-60.

47 White RP, Deane C, Vallance $P$, et al. Nitric oxide synthase inhibition in humans reduces cerebral blood flow but not the hyperemic response to hypercapnia. Stroke 1998;29:467-72.

48 Sato E, Sakamoto T, Nagaoka T, et al. Role of nitric oxide in regulation of retinal blood flow during hypercapnia in cats. Invest Ophthalmol Vis Sci 2003;44:4947-53.

49 Buerk DG, Atochin DN, Riva CE. Investigating the role of nitric oxide in regulating blood flow and oxygen delivery from in vivo electrochemical measurements in eye and brain. Adv Exp Med Biol 2003;530:359-70.

50 Luksch A, Polska E, Imhof A, et al. Role of NO in choroidal blood flow regulation during isometric exercise in healthy humans. Invest Ophthalmol Vis Sci 2003;44:734-9.

51 Schmetterer L, Findl O, Fasching $P$, et al. Nitric oxide and ocular blood flow in patients with IDDM. Diabetes 1997;46:653-8.
52 Wong TY, Duncan BB, Golden SH, et al. Associations between the metabolic syndrome and retinal microvascular signs: the Atherosclerosis Risk In Communities study. Invest Ophthalmol Vis Sci 2004;45:2949-54

53 Sowers JR, Epstein M, Frohlich ED. Diabetes, hypertension and cardiovascular disease. An update. Hypertension 2001;37:1053-9.

54 Estacio RO, Jeffers BW, Gifford N, et al. Effect of blood pressure control on diabetic microvascular complications in patients with hypertension and type 2 diabetes. Diabetes Care 2000;23(Suppl 2):B54-64.

55 American Diabetes Association. Standards of medical care for patients with diabetes mellitus. Diabetes Care 2003;26:S33-S50.

56 Harris MI, Klein R, Welborn TA, et al. Onset of NIDDM occurs at least 4-7 yr before clinical diagnosis. Diabetes Care 1992;15:815-19.

57 UK Prospective Diabetes Study Group. Tight blood pressure control and risk of macrovascular and microvascular complications in type 2 diabetes: UKPDS 38. BMJ 1998;317:703-713.

58 Matthews DR, Stratton IM, Aldington SJ, et al. Risks of progression of retinopathy and visual loss related to tight blood pressure control in type 2 diabetes mellitus: UKPDS 69. Arch Ophthalmol 2004;122:1631-40.

59 Knowler WC, Bennet PH, Ballintine EJ. Increased incidence of retinopathy in diabetics with elevated blood pressure. A six-year follow-up study in Pima Indians. N Engl J Med 1980;302:645-50.

60 Caballero AE. Metabolic and vascular abnormalities in subjects at risk for type 2 diabetes: the early start of a dangerous situation. Arch Med Res 2005;36:241-9.

61 Schram MT, Stehouwer CD. Endothelial dysfunction, cellular adhesion molecules and the metabolic syndrome. Horm Metab Res 2005;37/Suppl 1):49-55.

62 Landsberg L, Molitch M. Diabetes and hypertension: pathogenesis, prevention and treatment. Clin Exp Hypertens 2004;26:621-8.

63 El-Atat F, McFarlane SI, Sowers JR. Diabetes, hypertension, and cardiovascular derangements: pathophysiology and management. Curr Hypertens Rep 2004;6:215-23.

64 Dahlof B, Stenkula S, Hansson L. Hypertensive retinal vascular changes. Relationship to left ventricular hypertrophy and arteriolar changes before and after treatment. Blood Press 1992;1:35-44.

65 Heidbreder E, Huller U, Schafer B, et al. Severe hypertensive retinopathy. Increased incidence in renoparenchymal. hypertension. Am J Nephrol 1987;7:394-400.

66 Biesenbach G, Zazgornik J. High prevalence of hypertensive retinopathy and coronary heart disease in hypertensive patients with persistent microalbuminuria under short intensive antihypertensive therapy. Clin Nephrol 1994;41:211-18.

67 Wong TY, Coresh J, Klein R, et al. Retinal microvascular abnormalities and renal dysfunction: the Atherosclerosis Risk in Communities Study. J Am Soc Nephrol 2004; 15:2469-76.

68 Pontremoli R, Sofia A, Ravera M, et al. Prevalence and clinical correlates of microalbuminuria in essential hypertension. The MAGIC Study. Microalbuminuria: A Genoa Investigation on Complications. Hypertension 1997:30:1135-43.

69 Cuspidi C, Meani S, Salerno M, et al. Retinal microvascular changes and target organ damage in untreated essential hypertensives. $J$ Hypertens 2004;22:2095-102.

70 Cuspidi C, Macca G, Salerno M, et al. Evaluation of target organ damage in arterial hypertension: which role forqualitative funduscopic examination? Ital Heart J 2001;2:702-6.

71 Viazzi F, Parodi D, Leoncini G, et al. Optimizing global risk evaluation in primary hypertension: the role of microalbuminuria and cardiovascular ultrasonography. J Hypertens 2004;22:907-13.

72 Dodson PM, Kritzinger EE. Medical cardiovascular treatment trials: relevant to medical ophthalmology in 1997. Eye 1997;11(Pt 1):3-11.

73 Sperduto R, Holler R. Systemic hypertension and age-related maculopthay in the Framingham Study. Arch Ophthalmol 1986;104:216-19.

74 Bressler S, Maguire M, Bressler N, et al. Relationship of drusen and abnormalities of the retinal pigment epithelium to the prognosis of neovascular macular degeneration. Arch Ophthalmol 1990;108: 1442-7.

75 The Eye Disease Case Control Study Group. Risk factors for neovascular age-related macular degeneration. Arch Ophthalmol 1992;110:1701-8.

76 Klein R, Klein B, Franke T. The relationship of cardiovascular disease and its risk factors to age-related maculopathy. Ophthalmology 1993;100:406-14.

77 Macular Photocoagulation Study Group. Risk factors for choroidal neovascularisation in the second eye of patients with juxtafoveal or subfoveal choroidal neovascularisation secondary to age-related macular degeneration. Arch Ophthalmol 1997; 115:741-7.

78 Tielsch JM, Katz J, Sommer, et al. Hypertension, perfusion pressure, and primary open-angle glaucoma. A population-based assessment. Arch Ophthalmol 1995;113:216-21.

79 Jonas JB, Grundler AE. Prevalence of diabetes mellitus and arterial hypertension in primary and secondary open-angle glaucomas. Graefes Arch Clin Exp Ophthalmol 1998;236:202-6.

80 Ogden LG, HE J, Lydick E, et al. Long-term absolute benefit of lowering blood pressure in hypertensive patients according to $\mathrm{JNC}$ VI risk stratification. Hypertension 2000;35:539-43.

81 Owens $\mathrm{P}$, Atkins N, O'Brien E. Diagnosis of white coat hypertension by ambulatory blood pressure monitoring. Hypertension 1999;34:267-72.

82 Karter Y, Curgunlu A, Altinisik S, et al. Target organ damage and changes in arterial compliance in white coat hypertension. Is white coat innocent? Blood Press 2003;12:307-13.

83 Bidlingmeyer I, Burnier M, Bidlingmeyer $M$. Isolated office hypertension: a prehypertensive state? J Hypertens 1996;14:327-32. 
84 Falkner B, Daniels SR. Summary of the fourth report on the diagnosis, evaluation, and treatment of high blood pressure in children and adolescents. Hypertension 2004;44:387-8, Epub 2004 Sep 7.

85 Davis PH, Dawson JD, Riley WA, et al. Carotid intimal-medial thickness is related to cardiovascular risk factors measured from childhood through middle age: the Muscatine Study. Circulation 2001;104:2815-19.

86 Arnett DK, Glasser SP, McVeigh G, et al. Blood pressure and arterial compliance in young adults: the Minnesota Children's Blood Pressure Study. Am J Hypertens 2001;14:200-5.

87 Knoflach M, Kiechl S, Kind M, et al. Cardiovascular risk factors and atherosclerosis in young males: ARMY study (Atherosclerosis Risk-Factors in Male Youngsters). Circulation 2003;108:1064-9.

88 Sanchez A, Barth JD, Zhang L. The carotid artery wall thickness in teenagers is related to their diet and the typical risk factors of heart disease among adults. Atherosclerosis 2000;152:265-6.

89 Barnes VA, Treiber FA, Davis H. Impact of transcendental meditation on cardiovascular function at rest and during acute stress in adolescents with high normal blood pressure. J Psychosom Res 2001;51:597-605.

90 Daniels SR, Lipman MJ, Burke MJ, et al. The prevalence of retinal vascular abnormalities in children and adolescents with essential hypertension. Am J Ophthalmol 1991;111:205-8.

91 Daniels SR, Lipman MJ, Burke MJ, et al. Determinants of retinal vascular abnormalities in children and adolescents with essential hypertension. J Hum Hypertens 1993;7:223-8.

92 Wegmann-Burns M, Gugger M, Goldblum D. Hypertensive retinopathy. Lancet 2004;363:456.

93 Wong TY. Is retinal photography useful in the measurement of stroke risk? Lancet Neurol 2004;3:179-83.

94 Mitchell P, Leung H, Wang JJ. Retinal vessel diameter and open-angle glaucoma: the Blue Mountains Eye Study. Ophthalmology 2005; 112:245-50.

95 Klein R, Klein BE, Tomany SC. The relation of retinal microvascular characteristics to age-related eye disease: the Beaver Dam Eye Study. Am J Ophthalmol 2004;137:435-44.

96 Papastathopoulos KI, Jonas JB. Follow up of focal narrowing of retinal arterioles in glaucoma. Br J Ophthalmol 1999;83:285-9.

97 Dumskyj MJ, Aldnington SJ, Dore CJ. The accurate assessment of changes in retinal vessel diameter using multiple frame echocardiography synchronised fundus photography. Curr Eye Res 1996;15:625-32.

98 Knudtson MD, Klein BEK, Klein R, et al. Variation associated with measurement of retinal vessel diameters at different points in the pulse cycle. Br J Ophthalmol 2004;88:57-61.

99 Hague S, Hill DW. Postural changes in perfusion pressure and retinal arteriolar calibre. Br J Ophthalmol 1988;72:253-57.

100 Simon J, Svojgrova M, Simecek K, et al. Quantitative assessment of retinal vessel in relation to blood pressure. Hum Biol 1974;46:605-11.

101 Lanigan LP, Clark CV, Hill DW. Retinal circulation responses to systemic autonomic nerve stimulation. Eye 1988;4:12-17.
102 Larsen M, Berdiin Calmorn L, Bonnelycke M, et al. Retinal artery and vein diameters during pregnancy in diabetic women. Invest Ophthalmol Vis Sci 2005;46:709-13.

103 Bressler NM. Retinal arteriolar narrowing and risk of coronary heart disease. Arch Ophthalmol 2003;121:113-1.

104 Thybo NK, Stephens N, Cooper A, et al. Effect of antihypertensive treatment on small arteries of patients with previously untreated essential hypertension. Hypertension 1995;25:474-81.

105 Levy BI, Ambrosio G, Pries AR, et al. Microcirculation in hypertension: a new target for treatment? Circulation 2001; 104:735-40.

106 Rizzoni TD, Porteri E, Boari GEM, et al. Prognostic significance of smallartery structure in hypertension. Circulation 2003;108:2230-5

107 Ruilope LM, Schiffrin EL. Blood pressure control and benefits of antihypertensive therapy: does it make a difference which agents we use? Hypertension 2001;38:537-42.

108 Bock KD. Regression of retinal vascular changes by antihypertensive therapy. Hypertension 1984;6(Pt 2):158-62.

109 Sabbatini M, Tomassoni D, Di Tullio MA, et al. Neuroprotective effect of treatment with calcium antagonists on hypertensive retina. Clin Exp Hypertens 2002;24:727-40.

110 Ikram MK, de Jong FJ, Vingerling JR, et al. Are retinal arteriolar or venular diameters associated with markers for cardiovascular disorders? The Rotterdam Study. Invest Ophthalmol Vis Sci 2004;45:2129-34.

111 Prandoni P, Bilora F, Marchiori A, et al. An association between atheroslerosis and venous thrombosis. N Engl J Med 2003;348:1435-41.

112 Vink H, Constantinescu AA, Span JA, et al. Oxidized lipoproteins degrade the endothelial surface layer: implications for platelet-endothelial cell adhesion. Circulation 2000;101:1500-2.

113 Klein R, Klein BE, Moss S, et al. Retinal vascular abnormalities in persons with type 1 diabetes: the Wisconsin Epidemiologic Study of Diabetic Retinopathy. Ophthalmology 2003;110:2118-25.

114 Klein R, Klein BE, Moss S, et al. The relation of retinal vessel caliber to the incidence and progression of diabetic retinopathy: XIX: The Wisconsin Epidemiologic Study of Diabetic Retinopathy. Arch Ophthalmol 2004; 122:76-83.

115 Keen H, Chlouverakis C. Metabolic factors in diabetic retinopathy. In: Graymore CN, ed. Biochemistry of the retina. London: Academic Press, 1965:123-38.

116 Liao D, Wong TY, Klein R, et al. Relationship between carotid artery stiffness and retinal arteriolar narrowing in healthy middle-aged persons. Stroke 2004; 35:837-42.

117 Keith NM, Wagener HP, Barker NW. Some different types of essential hypertension: their course and their prognosis. Am J Med Sci 1939;197:332-43.

118 Porta M, Grosso A, Veglio F. Hypertensive retinopathy: there's more than meets the eye. (Review) J Hypertens 2005;23:683-96. 